\title{
Ganoderma disease of oil palm-A white rot perspective necessary for integrated control
}

\author{
R.R.M. Paterson \\ IBB-Institute for Biotechnology and Bioengineering, Centre for Biological Engineering, Universidade do Minho, \\ Campus de Gualtar, 4710-057 Braga, Portugal
}

Received 26 May 2006; received in revised form 20 November 2006; accepted 21 November 2006

\begin{abstract}
White rot fungi such as Ganoderma, are extraordinary organisms capable exclusively of degrading lignin to carbon dioxide and water: celluloses are then available as nutrients for the fungus. Oil palm (OP) is a highly significant crop in many countries and is prone to a rot caused by the fungus. It is necessary to consider this mode of attack as a white rot involving lignin biodegradation, for integrated control. The existing literature does not report this area and appears to be concerned particularly with the mode of spread and molecular biology of Ganoderma. The white rot perception opens up new fields such as (a) especially breeding/selecting for resistant cultivars of OP with high lignin content, (b) ensuring that the conditions for lignin decomposition are reduced, and (c) simply sealing damaged OP specifically to stop decay. It is likely that spread is by spores rather than roots. The knowledge gained can be employed in the rapid degradation of OP waste on the plantation floor by inoculating suitable fungi, and/or treating the waste more appropriately (e.g. chipping and spreading over the floor rather than windrowing). In conclusion, the control of Ganoderma on OP would benefit from further consideration of the process as one of white rot.
\end{abstract}

(C) 2006 Elsevier Ltd. All rights reserved.

Keywords: Ganoderma; Lignocellulose; Oil palm; White rot

\section{Introduction}

Ganoderma is a white rot fungus. The organism causes economic loss of oil palm (OP) in various regions around the world including Southeast (SE) Asia (Corley and Tinker, 2003), where the current author has had considerable experience of the crop disease. Perennial oilseed crops form a major component of rural economies throughout the wet lowland tropics of South, SE Asia and Oceania (Flood et al., 2000a). The basic premise of this review is that it is important for the control of Ganoderma disease to consider it specifically as a white rot fungus. This can be integrated with other approaches. The term "white rot" derives from the fungus degrading specifically the lignin component of wood while leaving white cellulose exposed.

Typically the fungus may attack already weakened OP as Ganoderma seldom seriously infects undamaged trees. A classic example is Ganoderma adspersum, which causes

E-mail address: russell.paterson@deb.uminho.pt. heart rot of beech and other broadleaved trees. The fungus is spread by spores and grows in the non-living tissues, which weakens the tree making it susceptible to wind damage. Appropriate mechanisms for control for OP may be embarked upon if these fundamental points are recognised (Paterson et al., 2000).

In general, Ganoderma establishes from airborne spores that enter wounds caused by shedding of branches, etc. The characteristic fruiting bodies release large numbers of spores thereby perpetuating the disease (J. Deacon, University of Edinburgh, personal communication). (F.R. Sanderson's (New Zealand) video on vast numbers of spores discharging from basdiocarps can be obtained from him to demonstrate vividly the phenomenon in Ganoderma on OP.) Deacon's web site, 〈http://helios.bto.ed.ac.uk/ bto/microbes/armill.htm $\rangle(21 / 12 / 06)$, includes images of the fungus on a tree and the metabolic pathway of cellulose biodegradation. Ganoderma obviously belongs to his, "Group 4-fungi that degrade the more recalcitrant polymers" (Deacon, 1997). The fungus is an efficient 
recycler rather than a pathogen per se, and essentially the disease is a form of extended biodeterioration. Interestingly, abundant bioactive secondary metabolites are produced by the genus which may have roles in the infection and spread of the disease, in addition to those related to medicine (Paterson, 2006b), although this is beyond the scope of the present review. There is still much to learn about disease aetiology and epidemiology of OP, which may be assisted with greater understanding of the basic biochemical processes. There follows a discussion on the extraordinary white rot process.

\section{Ganoderma from the white rot perspective}

It was encouraging that papers on delignification were included in some initial reports (Adaskaveg and Gilbertson, 1995; Martínez et al., 1995). However, this appreciation did not continue into subsequent papers permitting an unbalanced approach. Lignin biodegradation is probably a major part of the disease process. In particular, the macromolecular constitution of the OP needs to be considered.

The lignin component in plants is the rate-limiting step to biodegradation: it is a secondary metabolic process from which more energy is expended in degradation than can be obtained from utilisation. Lignin protects the more amenable cellulose and hemicelluloses from enzymatic attack by forming direct chemical bonds. The chemical structure of the polymeric lignin is complex (Fig. 1)

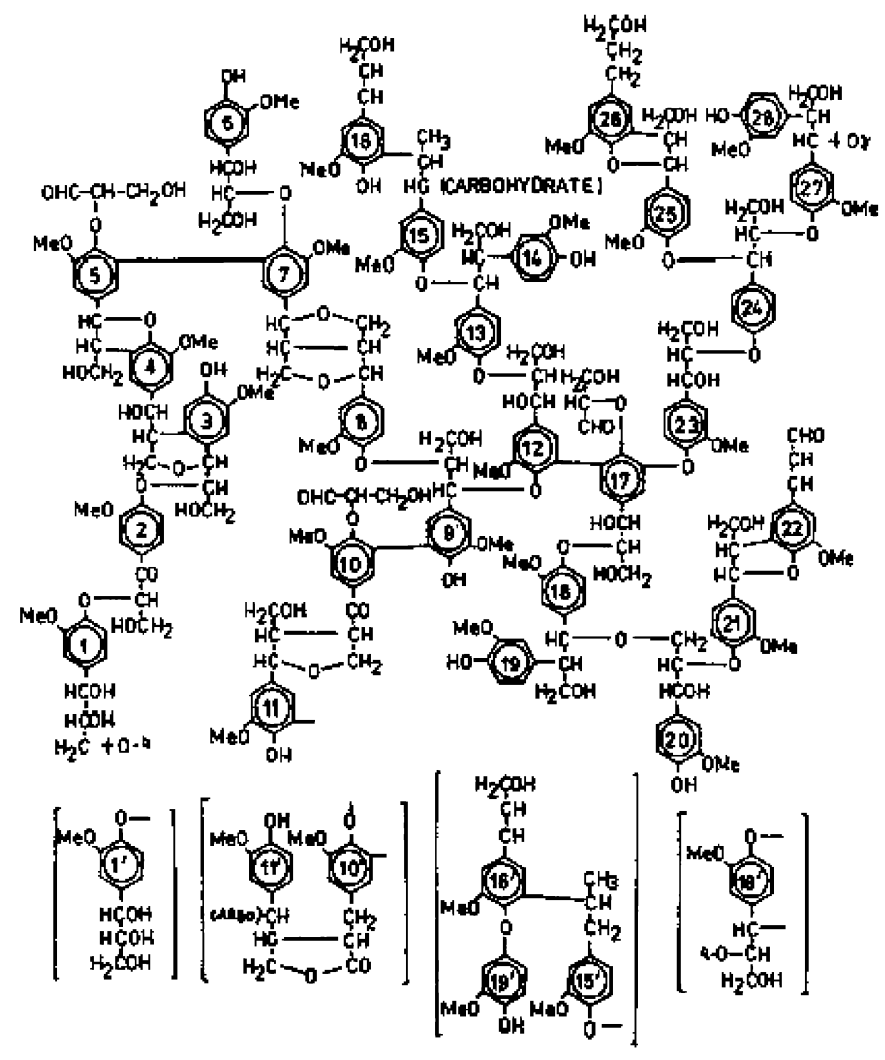

Fig. 1. Chemical structure of lignin. consisting of at least three monomeric building units. These can bond to another identical molecule and/or to the other two monomers to form a complicated three dimensional structure. Indeed the absolute chemical structure of lignin(s) remains to be fully determined. The white rot fungi (WRF) gain energy predominantly from cellulose which is available once lignin is degraded: however, other carbohydrates, such as starch (Paterson et al., 2000) and pectin are also present, although these are normally minor contributors.

Lignocelluloses (e.g. OP) are defined as plant or wood cells in which cellulose and hemicellulose are associated intimately with lignin. Lignin is a barrier to microbial attack, provides strength, and is a water impermeable seal across cell walls in the xylem tissue. The macromolecule is a phenylpropanoid polymer synthesised from the phenolic precursors, coniferyl, synapyl, and $p$-coumaryl alcohols. It has at least 12 different types of linkages such as aryl-ether and carbon-carbon bonds connecting the aromatic nuclei. These make its "biodegradability" very restricted. However, the exclusive ability of WRF to mineralise lignin to carbon dioxide and water relates to its ability to cleave the monomeric ring structures of the lignin monomers (Fig. 2). It is this that allows access to the energy-rich cellulose. WRF have been classified with respect to the ligninolytic enzymes they express (Ward et al., 2004): G. lucidum produces manganese peroxidases $(\mathrm{MnP})$, and laccases; similarly the enzymes of $G$. boninense (the provisional OP species (Corley and Tinker, 2003)) need to be determined. Lignin peroxidase (LIP) genes have been sequenced including those of G. applanatum (Martínez, 2002), and this area is ripe for determining relationships between taxa in the genus. It is necessary to consider the system further.

The WRF developed unspecific ligninolytic systems consisting of peroxidases and laccases (phenol oxidases: LAC) which employ an oxidative process. Three peroxidases have been observed: LIP, MnP and versatile peroxidase (VP). Peroxidases are heme-containing enzymes and require the presence of hydrogen peroxide. Laccases are multicopper phenol oxidases which oxidise phenols and

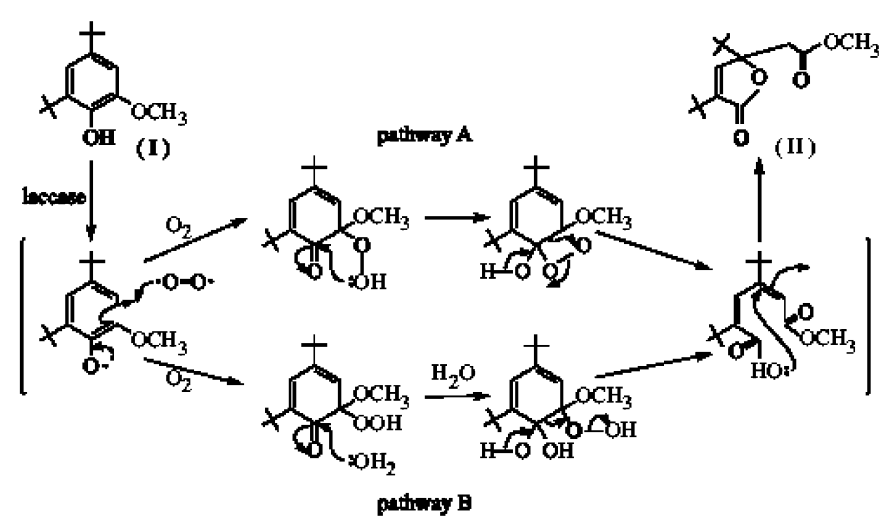

Fig. 2. Mechanisms of mucolactone (II) formation through the aromatic ring cleavage of the lignin model compound 4,6-di(t-butyl)guaiacol (I) by laccase of Trametes versicolor (Leonowicz et al., 2001). 
aromatic amines. These utilise dioxygen as an oxidant reducing it to water. There are at least eight enzymes involved directly. The fungi that produce these enzymes can be classified on the basis of the enzymes produced as mentioned. LIP is capable of oxidising most phenolic compounds through the generation of phenoxy radicals. However, it is also capable of oxidising non-phenolic aromatic substrates including the phenylpropanoid units of lignin. LIP can attack a wide-range of linkages suggesting it has a key role in lignin degradation. Furthermore, laccase oxidises lignin model compounds directly. The enzyme can also oxidise non-phenolic lignin. Some other enzymes, or enzyme-like-reactions include $\mathrm{H}_{2} \mathrm{O}_{2}$-generating enzymes, cellobiose dehydrogenase, and reactive oxygen species. The chapter of Ward et al. (2004) can be referred to for more details.

The biodegradation of the cellulose component is uncomplicated in comparison, not the least because it is constructed from only $\beta$-1, 4-glucosidic linkages between glucose units. Very generally the route is from crystalline cellulose " amorphic cellulose " short chain celluloses " cellobiose " glucose. However, the conversion of the crystalline material is in fact complex. Glucose is then available for further metabolism as occurs almost universally.

Finally, the data of Khalid et al. (2000) are useful in that they indicate how Ganoderma may attack living OP on the basis of the biodegradation of OP residues. For example, roots decayed much slower than the other residues indicating they may not be as important as a source of infection as other parts of the palm. On the other hand, leaflets degraded quickly and would seem a likely source of infection for other palms if $G$. boninense can utilise them. What work has been carried out to date?

\section{Previous studies on Ganoderma disease of $\mathrm{OP}$}

There has been a series of combined papers recently, implying Ganoderma is a very serious pathogen of OPs (see Bridge and Utomo (2005) and accompanying papers). Nevertheless, Likhitekaraj and Tummakate (2000) report that basal stem rot (BSR) is not a major problem in Thailand. Sariah and Zakaria (2000) claim that Ganoderma is not an aggressive pathogen and may be pathogenic only weakly to healthy palms. Problems in Papua New Guinea (PNG) are containable (see later). Miller et al. (2000) state Ganoderma is largely "saprobic" and exploits weakened hosts as parasites or secondary pathogens. Another description of the fungus is as a facultative saprophyte. In addition, Abdullah (2000) mentions Ganoderma living as an endophyte in coconuts. Does this occur in OP? Experimental controls for molecular techniques may need to consider this possibility and proving Koch's postulates will be made more difficult if true. Panchal and Bridge (2005) provide some interesting evidence for such a relationship where Ganoderma DNA was detected in asymptomatic OP.
On the other hand, Miller et al. (1999) refer to BSR as a "significant constraint". Flood et al. (2000b) state that BSR has been a serious disease of OP for over 80 years with severe economic loss in Malaysia and North Sumatra. Disease symptoms take years to develop, and are often totally absent in young palms. Also, percentage infection of palms is usually low (1-2\%) (Ariffin et al., 2000). Admittedly isolated losses of $80 \%$ have been recorded occasionally, but after repeated planting cycles. Losses of $20 \%$ are not economically significant. Miller et al. (1995) reported Ganoderma stem rot causing extensive losses in SE Asia. So it needs to be determined clearly just how serious is the disease.

BSR manifests in OP at about 10-12 years in Malaysia. Initial incidence is low at $1-2 \%$ as mentioned. However, it may be $25 \%$ at replanting (i.e. 25 years) (Ariffin et al., 2000 ). Disease levels of $10-20 \%$ have little effect on yield in term of fruit bunches due to compensatory growth, again reducing the economic significance of the rot. Despite these points, BSR caused by G. boninense is claimed to be the single major disease constraint to $\mathrm{OP}$ in the SE Asian region (Flood et al., 2000b).

The fungus was found to infect 1-2 years after planting with increases in 4-5 year old palms (Ariffin et al., 2000). Infection in inland soil in Malaysia and Indonesia on 7 year old plantations was low. Although incidence appeared high in OP grown inland. The symptoms comprise a mottling or yellowing of fronds followed by necrosis. Spear leaves eventually remain unopened. It is assumed that at least one-half of the basal stem has been killed by the fungus when foliar symptoms were observed. Young palms can take 6 months -2 years to die after the first symptoms, but mature palms take $2-3$ years, which is not very different in reality. There appears to be an error when symptoms are described as a "dry rot", and this term persists (Miller et al., 1999; Lim and Fong, 2005). Dry rot is caused by Serpula lacrymans and is quite different (Ward et al., 2004). OP eventually collapses leaving diseased bole tissue in the ground. Basidiomata may develop at the stem base, leaf base, or infected root; the location provides a guide to the diseased area inside the palm. Finally, the name $G$. boninense was suggested from morphological examination although other taxa appeared also to be present (Ariffin et al., 2000): Corley and Tinker (2003) prefer simply Ganoderma.

There is still a considerable amount to be revealed concerning infection and spread within OP plantations. Spore dispersal must be of crucial importance over root to root (Sanderson, 2005; personal communication). Abdullah (2000) mentions Ganoderma living as an endophyte in coconuts (see Panchal and Bridge (2005) for OP) and the study favours spread from independent secondary inocula. Their work does not support root to root spread (and)/or airborne spore spread. However, roots were thought to be the mode of spread. It appeared to be accepted generally that infection results from contact between healthy roots and diseased tissue remaining in the 
soil. Surprisingly, the role of basidiospores remains unclear (Ariffin et al., 2000). Weakening of the palm may predispose it to infection.

Initially the disease was associated with old palms in the early years of study. However, the trend has changed (Flood et al., 2000b). BSR began after the 6th year and increased rapidly from the 11th. The previous crop is important, with infected coconut palms permitting rapid infection. Soil types could usefully be further investigated: The nutrient content of the soil affects the progress of the disease which may relate to the effect of nutrients on enzyme production by the fungus. Planting techniques may also be a factor (Ariffin et al., 2000). In addition, Soepena et al. (2000) state that $G$. boninense is the most destructive OP disease in SE Asia. It is considered to be from root to root contact, the usual perception, with spore spread from wind also possible. On the other hand, Miller et al. (1999) suggest that root to root contact may not be the manner of spread and that basidiospore dispersal or contact with residual inoculum is, although both could be involved if true. Symptoms of BSR appear long after planting. Nevertheless, it is considered that spread is from root to root contact once a few palms are infected (Flood et al., 2000b). The role of basidiospores may not be direct - they might contaminate "dead" material which infects OP subsequently.

Sanderson et al. (2000) support the view that roots come in contact with infected debris and spread disease in that manner, despite this not involving spores. It was interesting that isolates used in Bridge et al. (2004) were not identical as they might be expected to be as follows from Sanderson et al.'s observation. The authors emphasise the importance of basidiospores which is not the case with other researchers and to ignore this route would be a severe mistake. Bridge et al. mention that almost all isolates differed one from another. This is probably from the formation of new dikaryotic strains from monokaryotic ones. The other option of each infection being from different infected debris seems unlikely as why would each infected piece of debris be different? Ganoderma infections are claimed to occur over periods of years (Bridge and Utomo, 2005), which is much longer than the time scales of more familiar and serious fungal plant pathogens (e.g. Fusarium oxysporum). Nevertheless, the rots are important economically.

Many cultural techniques and practices have indeed been developed (Durand-Gasselin et al., 2005). The differences in susceptibility reported may relate to differences in the lignin content of the "genetic resources", and again indicates a legitimate method for controlling the disease that by developing OP with more, and/or more resistant, lignin infection may be reduced. It is noted that the observed difference in plant cultivars may not support the notion of a true difference in susceptibility. In these cases, disease development took 20 and 8 years. It is stated that losses of $20 \%$ are generally not economically significant, and there is no such thing as a Ganoderma-free cultivar. It appears that BSR begins in young palms and spreads but without an explosive exponential phase.

OP can exhibit BSR following conversion after rubber (Flood et al., 2005) which may occur 10-14 years after planting. It seems that root contact is important from debris although this may also be important for seedlings (see later): this does not take into account spread of the disease from spores. An improved method to a "push of a metal rod" for determining decay is possible, e.g. ergosterol analysis or enzyme digestibility (Paterson et al., 2000). BSR is the most destructive disease in OP (Susanto et al., 2005): $G$. boninense is beginning to be found even on young plants: the disease is also observed at the seedling stage. The fungus is claimed to be soil borne, although it can be spread by spores.

However, it is stated that Ganoderma attacks the root system (Utomo et al., 2005) from second and subsequent planting cycles. This appears to be only in seedlings according to Sanderson (2005) and then infection is by airborne spores. Pilotti et al. (2003) indicate a great deal of genetic diversity towards this end which may be useful in distinguishing the fungus on dead, compared to living, OP. Lim and Fong (2005) imply that spores from fruiting bodies are sources of inocula for further infections with root contact also being a possibility. They mention that symptoms on seedlings are a "dry rot" which is a mistake as the fungus is a white rot (and see previously). Hasan et al. (2005) suggest that infection from a large inoculum in dead material allowed invasion of the living material. However, the macromolecules which would be invaded are not living tissue. There is no particular reason to suggest that the fungus needs to overcome truly living cells first as the dead wood could be completely exposed: spores can come in contact with freshly cut palm tissue allowing infection as Panchal and Bridge (2005) mention.

It is implied that disease levels are under control in PNG (Pilotti, 2005). So there may be benefit to be gained from a direct comparison of this country with SE Asia where the disease appears more serious. Basidiospores are implicated as the predominant infection source of palms, although, surprisingly, this is not the conventional view. Furthermore, Sanderson (2005) provided an adroit insight into the spread of the disease where root contact is important in seedling infection but spore dispersal is more significant later. BSR is only part of the disease cycle. The cause for the switch from endemic form to an "affecting trees stage" (Sankaran et al., 2005) would be illuminating, but is surely elusive. It is noticeable that the fungus is not discussed in terms of it being a WRF in relation to OP. The taxonomy of the fungus is a field of considerable potential for academic research and will be considered next together with methods for identifying the fungus.

\section{Ganoderma systematics and diagnosis}

This is not intended to be a comprehensive taxonomic review. Many issues that relate to specific control of 
particular taxa and diagnostics are within this field. Ganodermataceae are WRF of hardwoods. They degrade lignin preferentially until the white cellulose is visiblehence the name. However, the taxonomy is confused within Ganoderma: Polyporus lucidus was the first described species of the genus (Seo and Kirk, 2000) and G. boninense is associated with the OP disease. Ryvarden (1995) emphasised that the taxonomy of Ganoderma was in a deplorable state. Moncalvo (2000) demonstrated by rDNA sequence data indications of some inadequacy of morphological characters. Nevertheless, the palm clade was heterogeneous containing various taxa and requires further investigation. A surprisingly large amount of embryonic chemotaxonomy has been undertaken within the genus (Paterson, 2006b) which relates to the huge range of bioactive compounds discovered.

Otherwise, Hong and Jung (2004) investigated the characteristics and structures of the single locus mt SSU rDNA for a phylogenetic study of Ganoderma in perhaps the most sophisticated investigation to date. The strains of Ganoderma species were divided into six monophyletic groups: (1) G. colossus made a distinct basal lineage from other Ganoderma species and the genus name Tomophagus appeared to be valid; (2) G. applanatum and G. lobatum clustered in subgenus Elfvingia (yet another name) as a monophyletic group; (3) G. tsugae from North America and G. valesiacum from Europe were closely related and were both from conifers. G. oregonense and strains labelled G. lucidum from Europe and Canada were grouped with G. tsugae and G. valesiacum; (4) G. lucidum living on United States hardwoods and Taiwan were grouped with $G$. resinaceum, $G$. pfeifferi and $G$. subamboinense var. laevisporum, and they all produced chlamydospores; (5) two and three American strains of G. lucidum and G. resinaceum respectively were conspecific and (6) strains of G. lucidum from Korea and Japan were monophyletic and were distinguished from the species from Europe and North America. Host relationships, the presence of chlamydospores in culture and the phylogenetic relationships proved to be important characteristics in the systematics. It would appear that geographical region is significant. Of course, it is necessary to determine how the OP isolates compare to these species. In summary, a complex situation, implying that names given to Ganoderma should be treated with caution.

Miller et al. (1995) mentioned that 15 species were putative pathogens of OP. As early as 1995, pectinase isozymes did correspond to hosts of origin with palms and OP strains formed a distinct cluster in a dendrogram, although the strains were heavily biased towards OP. Isolates attacking OP could not be differentiated from saprophytes. Chaotic taxonomic divisions are still referred to in Miller et al. (2000). BSR species concepts were very confused. A great deal of discussion is provided on pectinases although they may only be of minor relevance in white rots. Nevertheless, Bridge et al. (2004) state that pectin and pectin biodegradation are important in the pathogenicity of OP.
Pilotti et al. (2003) found intraspecific variability amongst $G$. boninense to be high. The isolates were distinct predominantly from a genetic standpoint, and there was no direct relationship between isolates on neighbouring or spatially separated palms. They concluded that sexual reproduction is a significant component of the epidemiology of the disease. On the other hand, Bridge et al. (2000) demonstrated that BSR on OP is a single taxon. Miller et al. (1999) found a great deal of variability between strains: strains from the same palm differing in some cases. The term "dry rot" was erroneously used in this document to describe BSR lesions.

The possibility of false negative results were not considered in the studies on Ganoderma using PCR methods. Hoorfar et al. (2004) stated that the use of internal amplification controls (IAC) are mandatory, and Paterson (2004) indicated that inhibition can occur in pure cultures of the penicillia via secondary metabolites. Furthermore, the IAC issue for fungi (including Ganoderma) is reviewed extensively in Paterson (2007). Related to this, Ganoderma are known to produce numerous secondary metabolites (Paterson, 2006b) some with significant structure/activity effects on nucleic acids and proteins (Mizushina et al., 1999), and so this fungus cannot be exempt from IAC.

Utomo et al. (2005) reported specific nucleic acid methodology to characterise pathogenic Ganoderma. The results indicated that $\mathrm{OP}$ strains are a single species although whether the PCR of the other taxa were inhibited cannot be determined without an IAC. Several Ganoderma taxa were pathogenic to OP (Pilotti, 2005) and unsurprisingly there is confusion regarding species concepts. G. zonatum is also a pathogen, or what is described as "weakly pathogenic". The fungus involved in PNG has been tentatively identified also as $G$. boninense (Pilotti, 2005).

Until recently at least, the detection of the disease was based on external symptoms and is only confirmed when basidiomata appeared. Otherwise the symptoms could be caused by different organisms. It is unclear whether any of the new techniques described have been employed on a routine basis to supplant this traditional method. Issues on how to take representative samples from even a single OP need to be addressed.

A selective medium had some merit for early detection (Ariffin et al., 2000). Molecular fingerprinting is recommended to confirm the origins of Ganoderma in the environment (Flood et al., 2000b) although the AFLP profiles provided appeared not to be identical in contradiction to what the authors claimed. The techniques of Utomo and Niepols (2000) permitted detection of Ganoderma in infected tissue. Much greater amounts of testing are required and particularly of healthy OP which may contain the fungus (Panchal and Bridge, 2005).

Darmono (2000) also described antibody-based methods which were in the early development stage. Utomo et al. (2005) reported on specific nucleic acid methodology to 
characterise pathogenic Ganoderma: the results indicate that OP isolates belonged to a single species. Because IAC were not employed, this conclusion must be in doubt (Paterson, 2007). They mention that the results of Pilotti et al. (2000) are not specific and confirm that RAPD and AFLP are extremely sensitive to contamination. In addition, the between-run variability of RAPDs is high.

A method is required for separating Ganoderma from dead OP or soils, from those that degrade healthy OP. Towards this end, Pilotti et al. (2003) indicated a great deal of genetic diversity which may be useful. The concept of a Ganoderma endophyte needs to be considered as suggested for coconut (see above) and not the least because seedlings have the disease (Sanderson, 2005). Nucleic acid methods need to take this possibility into account in terms of suitable experimental controls. Finally, the diversity of secondary metabolites produced by the genus, including the OP isolates, requires to be further employed in chemotaxonomy (Paterson, 2006b) and as possible diagnostic compounds within infected OP.

Can the considerations of a fungus being a white rot be employed for more effective control of OP?

\section{Ganoderma control}

A variety of methods are required for an integrated approach to disease control. Soepena et al. (2000) considered that all infected plant material be treated with a Trichoderma biofungicide - it is yet to be determined that this would be successful. Great care would need to be taken that they did not contaminate the final product of palm oil as Trichoderma spp. produce toxic secondary metabolites (Paterson, 2006a). Disease avoidance involves reducing infection sources at the time of clearing old stands (Flood et al., 2000b) which is the basic minimum procedure. The conclusions of Sanderson et al. (2000) involve fundamental rethinking in epidemiology of the disease - removal of the old root system is probably not important. They mentioned that total control was unattainable.

Rolph et al. (2000) stated that major constraints to disease control are the lack of sufficient information on variation in Ganoderma species associated with disease and their mode of reproduction. However, it is debatable just how useful this indirect information is to the reality of control in the field. Debris left in the field is reported to be a very important source of infection (Flood et al., 2005) and much of the management naturally involves removal, particularly at replanting. Spreading and chopping (Ooi and Heriansyah, 2004) over a wide area may be a better option than windrowing (Flood et al., 2005). Also, spores can come in contact with freshly cut palm tissue (Panchal and Bridge, 2005) allowing infection which provides a procedure for control by sealing the cuts. It is suggested again, Panchal and Bridge (2005), that infected debris and fruiting bodies are removed prior to planting to control the disease, which is self-evident.
On the other hand, an appreciation of how the living palm is degraded leads naturally to methods for control, e.g. breeding/selection for high, or more resistant, lignincontaining palms (see Casler et al. (2002) for modifying lignin in herbaceous plants), and using WRF to degrade lc wastes on the plantation floor. Research into high, or resistant lignin OP requires particular mention as an area which could revolutionise the way OP are managed by the industry.

When OP are felled they create a vast amount of waste product which has been burned in the past. However, this was banned in Malaysia due to persistent haze problems. A potential solution is enhancing the degradation of the waste on the plantation floor (Paterson et al., 2000). Essentially this involves increasing the digestibility of the OP waste by treatment with lignin degrading fungi and is an adaptation of the "palo podrido" phenonomom (Martínez et al., 1995). Useful data are presented in Khalid et al. (2000) on the decomposition process of palm residues which effectively acts as a control for any proposed accelerated process. A two-stage degradation of trunks was apparent with rapid and slow stages for the first 10 and remaining 8 months, respectively. An average of $15 \%$ dry matter remained.

An assessment was made of fungal isolates collected in the region for ligninase, cellulase, and amylase in agar plate tests with a view to degrading OP by-products (Paterson et al., 2000). The OP Ganoderma produced ligninases confirming the white rot status. Marasmius strains had high ligninase and amylase levels but no cellulase was detected. These traits could have been effective for increasing the cellulose digestibility of the substrate. However, many did not grow on OP. Hydnum sp. and Pleurotus djamor did grow well and better than the fastest-growing Ganoderma. This is a useful feature also as an inoculated strain would need to outgrow indigenous Ganoderma. In a similar vein, two Lenzites and Marasmius strains gave the highest weight loss. Ergosterol was used to measure growth in the study which is the recommended technique for estimating Ganoderma disease of OP by the present author (Flood et al., 2005). Enzyme digestibility assays are also very desirable to determine the amount of decay and if treatments are in fact increasing the digestibility of the substrate. Respirometry may be useful although the equipment involved is expensive and provides indirect data. In conclusion, interesting and encouraging results were obtained within a short piece of work. A cell free enzyme preparation of ligninases (Rodríguez Couto et al., 2006) could be applied to the waste, which would avoid relying on growth of a fungus in the plantations. Finally, Susanto et al. (2005) mention briefly in the paper abstract that biodegradation studies were being undertaken to completely degrade OP material left on the ground. Strangely there are no details in the paper and so conclusions cannot be made.

On a recapitulation of the theme, WRF need to attack polysaccharides and lignin to degrade wood (e.g. OP). 
When the flow of sugar ceases, the fungus "starves" and converts to secondary metabolism which promotes lignin degradation in a cyclical manner. Carbon, nitrogen and manganese are critical variables and so altering these as a control method may prevent Ganoderma attack. Limiting carbon, nitrogen and sulphur can trigger lignin degradation and conversely ensuring they are available to OP may limit the rot. These nutrients could conceivably be supplied by soil application with a view to control the disease in addition to them being used as fertilizers. Fertilisers are, of course, added which contain some of these minerals but the point here is to control disease not to improve the growth of the OP per se. The existing literature does not consider control from this perspective, although the use of soil amendments is mentioned as a possibility by Sariah and Zakaria (2000).

Kee (2004) stated that OP trunks were a tremendous pool of nutrients which could be made available to subsequent generations of OP. However, few nutrients were released although decomposition was rapid. The work mentions that the basal segment is higher in lignin than the upper section. This might indicate that the upper region may be degraded quicker than the basal region. Furthermore, methods for spreading and pulverising OP have been described resulting in rapid decomposition with benefits regarding pest control (including Ganoderma) and the avoidance of burning (Ooi and Heriansyah, 2004). It is pointed out by the current author that pulverisation will be energy demanding, and, together with the cost of machinery, the whole process may be uneconomic.

\section{Conclusions}

A number of these can be made by comparing 1995 to the near-current situation: (a) the phenomenon of Ganoderma on $\mathrm{OP}$ as a white rot fungus requires to be addressed if an integrated approach is desired, (b) an important redirection of effort into developing high, or resistant, lignin $\mathrm{OP}$ is required, (c) the severity of the disease needs to be determined objectively, (d) the fungus causing the disease is now called $G$. boninense, (e) the method of spread is not established definitively but is almost certainly by airborne spores, (f) nucleic acid methods in particular have been developed but IAC have not been employed making conclusions difficult or impossible, and (g) more individual, independent and scientific papers are required. White rot is the defining mode of action of the fungus and needs to be studied in relation to OP. An appreciation of this will lead to optimal methods for control of OP losses as described herein.

\section{Acknowledgement}

The author was supported by Grant SFRH/BPD/14923/ 2004 from Fundação para a Ciência e a Tecnologia (FCT), Portugal.

\section{References}

Abdullah, F., 2000. Spatial and sequential mapping of the incidence of basal stem rot of oil palms (Elaeis guineenis) on a former coconut (Cocus nucifera) plantation. In: Flood, J., Bridge, P.D., Holderness, M. (Eds.), Ganoderma Diseases of Perennial Crops. CABI Publishing, Wallingford, UK, pp. 183-194.

Adaskaveg, J.E., Gilbertson, R.L., 1995. Wood decay caused by Ganoderma species in the G. lucidum complex. In: Buchanan, P.K., Hsea, R.S., Moncalvo, J.M. (Eds.), Proceedings of Contributed Symposium 59. Fifth International Mycological Congress, Vancouver, Canada, pp. 79-93.

Ariffin, D., Idris, A.S., Singh, G., 2000. Status of Ganoderma in oil palm. In: Flood, J., Bridge, P.D., Holderness, M. (Eds.), Ganoderma Diseases of Perennial Crops. CABI Publishing, Wallingford, UK, pp. 49-68.

Bridge, P.D., O'Grady, E., Pilotti, C.A., Sanderson, F.R., 2000. Development of molecular diagnostics for the detection of Ganoderma isolates pathogenic to oil palm. In: Flood, J., Bridge, P.D., Holderness, M. (Eds.), Ganoderma Diseases of Perennial Crops. CABI Publishing, Wallingford, UK, pp. 225-247.

Bridge, P.D., Singh, T., Arora, D.K., 2004. The application of molecular markers in the epidemiology of plant pathogenic fungi. In: Arora, D.K. (Ed.), Fungal Biotechnology in Agriculture, Food, and Environmental Applications. Marcel Dekker, New York, pp. 57-68.

Bridge, P.D., Utomo, C., 2005. Editorial. Mycopathologia 159, 91.

Casler, M.D., Buxton, D.R., Vogel, K.P., 2002. Genetic modification of lignin concentration affects fitness of perennial herbaceous plants. TAG Theor. Appl. Genet. 104, 127-131.

Corley, R.H.V., Tinker, P.B., 2003. The Oil Palm. Blackwell Publishing, Oxford.

Darmono, T.W., 2000. Ganoderma in oil palm in Indonesia: current status and prospective use of antibodies for the detection of infection. In: Flood, J., Bridge, P.D., Holderness, M. (Eds.), Ganoderma Diseases of Perennial Crops. CABI Publishing, Wallingford, UK, pp. 249-266.

Deacon, T.W., 1997. Modern Mycology. Blackwell Science, Oxford.

Durand-Gasselin, T., Asmandy, H., Flori, A., Jacquemard, J.C., Hayun, Z., Breton, F., de Franqueville, H., 2005. Possible sources of genetic resistance in oil palm (Elaeis guineensis Jacq.) to basal stem rot caused by Ganoderma boninense - prospects for future breeding. Mycopathologia 159, 93-100.

Flood, J., Bridge, P.D., Holderness, M., 2000a. Preface. Ganoderma Diseases of Perennial Crops. CABI Publishing, Wallingford, UK.

Flood, J., Husan, Y., Turner, P.D., O'Grady, E.B., 2000b. The spread of Ganoderma from infective sources in the filed and its implications for management of the disease in oil palm. In: Flood, J., Bridge, P.D., Holderness, M. (Eds.), Ganoderma Diseases of Perennial Crops. CABI Publishing, Wallingford, UK, pp. 101-112.

Flood, J., Keenan, L., Wayne, S., Hasan, Y., 2005. Studies on oil palm trunks as sources of infection in the field. Mycopathologia 159, 101-107.

Hasan, Y., Foster, H.L., Flood, J., 2005. Investigations on the causes of upper stem rot (USR) on standing mature oil palms. Mycopathologia 159, 109-112.

Hong, S.G., Jung, H.S., 2004. Phylogenetic analysis of Ganoderma based on nearly complete mitochondrial small-subunit ribosomal DNA sequences. Mycologia 96, 742-755.

Hoorfar, J., Cook, N., Malorny, B., de Medici, D., Abdulmawjood, A., Fach, P., 2004. Diagnostic PCR: making internal amplification control mandatory. J. Appl. Microbiol. 96, 221-222.

Kee, K.K., 2004. Nutrient reserves and recycling from oil palm trunks at replanting. In: Proceedings of the Fourth International Crop Science Congress on New Direction For a Diverse Planet, Brisbane, < www.cropscience.org.au $>$, 25/5/06.

Khalid, H., Zin, Z.Z., Anderson, J.M., 2000. Decomposition processes and nutrient release patterns of oil palm residues. J. Oil Palm. Res. 12, 46-63. 
Leonowicz, A., Cho, N.-S., Luterek, J., Wilkolazka, A., WojtasWasilewska, M., Matuszewska, A., Hofrichter, M., Wesenberg, D., Rogalski, J., 2001. Fungal Laccase: properties and activity on lignin. J. Basic Microbiol. 41, 185-227.

Likhitekaraj, S., Tummakate, A., 2000. Basal stem rot of oil palm in Thailand caused by Ganoderma. In: Flood, J., Bridge, P.D., Holderness, M. (Eds.), Ganoderma Diseases of Perennial Crops. CABI Publishing, Wallingford, UK, pp. 69-70.

Lim, H.P., Fong, Y.K., 2005. Research on basal stem rot (BSR) of ornamental palms caused by basidiospores from Ganoderma boninense. Mycopathologia 159, 171-179.

Martínez, A.T., 2002. Molecular biology and structure function of lignindegrading heme peroxidases. Enzyme Microb. Technol. 30, 425-444.

Martínez, A.T., Barrasa, J.M., Martínez, M.J., Almendros, G., Blanco, M., González, A.E., 1995. Ganoderma australe: a fungus responsible for extensive delignification of some Australian hardwoods. In: Buchanan, P.K., Hsea, R.S., Moncalvo, J.M. (Eds.), Proceedings of Contributed Symposium 59. Fifth International Mycological Congress, Vancouver, Canada, pp. 67-77.

Miller, R.N.G., Holderness, M., Bridge, P.D., Paterson, R.R.M., Sariah, M., Hussin, M.D.Z., Hilsey, E.J., 1995. A multi-disciplinary approach to the characterisation of Ganoderma in oil-palm cropping systems. In: Buchanan, P.K., Hsea, R.S., Moncalvo, J.M. (Eds.), Proceedings of Contributed Symposium 59. Fifth International Mycological Congress, Vancouver, Canada, pp. 57-66.

Miller, R.N.G., Holderness, M., Bridge, P.D., Chung, G.F., Zakaria, M.H., 1999. Genetic diversity of Ganoderma in oil palm plantings. Plant Pathol. 48, 595-603.

Miller, R.N.G., Holderness, M., Bridge, P.D., 2000. Molecular and morphological characterization of Ganoderma in oil-palm plantings. In: Flood, J., Bridge, P.D., Holderness, M. (Eds.), Ganoderma Diseases of Perennial Crops. CABI Publishing, Wallingford, UK, pp. 159-182.

Mizushina, Y., Takahashi, N., Hanashima, L., Koshino, H., Esumi, Y., Uzawa, J., Sugawara, F., Sakaguchi, K., 1999. Lucidenic acid O and lactone, new terpene inhibitors of eukaryotic DNA polymerases from a basidiomycete, Ganoderma lucidum. Bioorg. Med. Chem. 7, 2047-2052.

Moncalvo, J.-M., 2000. Systematics of Ganoderma. In: Flood, J., Bridge, P.D., Holderness, M. (Eds.), Ganoderma Diseases of Perennial Crops. CABI Publishing, Wallingford, UK, pp. 23-45.

Ooi, L.-H., Heriansyah, 2004. Palm pulverisation in sustainable oil palm replanting. In: Proceedings of the Fourth International Crop Science Congress on New Direction For a Diverse Planet, Brisbane, < www.cropscience.org.au $>, 31 / 1 / 06$.

Panchal, G., Bridge, P.D., 2005. Following basal stem rot in young oil palm plantings. Mycopathologia 159, 123-127.

Paterson, R.R.M., 2007. Internal amplification controls have not been employed in diagnostic fungal PCR, hence potential false negative results. J. Appl. Microbiol. 102, 1-10.

Paterson, R.R.M., 2004. The isoepoxydon dehydrogenase gene of patulin biosynthesis in cultures and secondary metabolites as candidate PCR inhibitors. Mycol. Res. 108, 1431-1437.

Paterson, R.R.M., 2006a. Fungi and fungal toxins as weapons. Mycol. Res. 110, 1003-1010.

Paterson, R.R.M., 2006b. Ganoderma - a therapeutic fungal biofactory. Phytochemistry 67, 1985-2001.

Paterson, R.R.M., Holderness, M., Kelley, J., Miller, R., O'Grady, E., 2000. In vitro diodegradation of oil-palm stem using macroscopic fungi from South East Asia: a preliminary investigation. In: Flood, J., Bridge, P.D., Holderness, M. (Eds.), Ganoderma Diseases of Perennial Crops. CABI Publishing, Wallingford, UK, pp. 129-138.
Pilotti, C.A., 2005. Stem rots of oil palm caused by Ganoderma boninense: pathogen biology and epidemiology. Mycopathologia 159, 129-137.

Pilotti, C.A., Sanderson, F.R., Aitken, E.A.B., 2003. Genetic structure of a population of Ganoderma boninense on oil palm. Plant Pathol. 52, 455-463.

Pilotti, C.A., Sanderson, F.R., Aitken, E.A.B., Bridge, P.D., 2000. Genetic variation in Ganoderma spp. from Papua New Guinea as revealed by molecular (PCR) methods. In: Flood, J., Bridge, P.D., Holderness, M. (Eds.), Ganoderma Diseases of Perennial Crops. CABI Publishing, Wallingford, UK, pp. 195-204.

Rodríguez Couto, S.R., Rodríguez, A., Paterson, R.R.M., Lima, N., Teixeira, J.A., 2006. Laccase activity from the fungus Trametes hirsuta using an air-lift bioreactor. Lett. Appl. Microbiol. 42, 612-616.

Rolph, H., Wijesekara, R., Lardner, R., Abdullah, F., Kirk, P.M., Holderness, M., Bridge, P.D., Flood, J., 2000. Molecular variation in Ganoderma from oil palm, coconut and betelnut. In: Flood, J., Bridge, P.D., Holderness, M. (Eds.), Ganoderma Diseases of Perennial Crops. CABI Publishing, Wallingford, UK, pp. 205-221.

Ryvarden, L., 1995. Can we trust morphology in Ganoderma? In: Buchanan, P.K., Hsea, R.S., Moncalvo, J.M. (Eds.), Proceedings of Contributed Symposium 59. Fifth International Mycological Congress, Vancouver, Canada, pp. 19-24.

Sanderson, F.R., 2005. An insight into dispersal of Ganoderma boninense on oil palm. Mycopathologia 159, 139-141.

Sanderson, F.R., Pilotti, C.A., Bridge, P.D., 2000. Basidiospores: their influence on our thinking regarding a control strategy for basal stem rot. In: Flood, J., Bridge, P.D., Holderness, M. (Eds.), Ganoderma Diseases of Perennial Crops. CABI Publishing, Wallingford, UK, pp. 113-119.

Sankaran, K.V., Bridge, P.D., Gokulapalan, C., 2005. Ganoderma disease of perennial crops in India-an overview. Mycopathologia 159, $143-152$.

Sariah, M., Zakaria, H., 2000. The use of soil amendments for the control of basal stem rot of oil-palm seedlings. In: Flood, J., Bridge, P.D., Holderness, M. (Eds.), Ganoderma Diseases of Perennial Crops. CABI Publishing, Wallingford, UK, pp. 89-99.

Seo, G.S., Kirk, P.M., 2000. Ganodermataceae: nomenclature and classification. In: Flood, J., Bridge, P.D., Holderness, M. (Eds.), Ganoderma Diseases of Perennial Crops. CABI Publishing, Wallingford, UK, pp. 129-138.

Soepena, H., Purba, R.Y., Pawirosukarto, S., 2000. A control strategy for basal stem rot (Ganoderma) on oil palm. In: Flood, J., Bridge, P.D., Holderness, M. (Eds.), Ganoderma Diseases of Perennial Crops. CABI Publishing, Wallingford, UK, pp. 83-88.

Susanto, A., Sudharto, P.S., Purba, R.Y., 2005. Enhancing biological control of basal stem rot (Ganoderma boninense) in oil palm plantations. Mycopathologia 159, 153-157.

Utomo, C., Niepols, F., 2000. The development of diagnostic tools for Ganoderma in oil palm. In: Flood, J., Bridge, P.D., Holderness, M. (Eds.), Ganoderma Diseases of Perennial Crops. CABI Publishing, Wallingford, UK, pp. 235-247.

Utomo, C., Werner, S., Niepold, F., Deising, H.B., 2005. Identification of Ganoderma, the causal agent of basal stem rot disease in oil palm using a molecular method. Mycopathologia 159, 159-170.

Ward, G., Hadar, Y., Dosoretz, C.G., 2004. The biodegradation of lignocellulose by white rot fungi. In: Arora, D.K. (Ed.), Fungal Biotechnology in Agriculture, Food, and Environmental Applications. Marcel Dekker, New York, pp. 393-407. 